\title{
Histological study of two cases of Coxsackie B virus pneumonia in children
}

\author{
T. H. FLEWETT
}

\author{
From the Regional Virus Laboratory, East Birmingham Hospital, Birmingham
}

SYNOPSIS Two cases of interstitial pneumonia are described. They were characterized by mononuclear cell infiltration of the alveolar walls and protein-rich exudate into the alveolar cavities, with localized hyaline membrane formation. Coxsackie B5 virus was isolated from the lungs of both patients at necropsy.

It has been known for some time that the group B Coxsackie viruses are capable of producing respiratory tract infections and pneumonia in children. Pleurisy associated with Coxsackie infections is probably not at all uncommon, though clinically it is frequently difficult to distinguish from the acute pain produced by movement of the chest wall when there is localized myositis of the intercostal muscles. Holzel, Parker, Patterson, Cartmel, White, Purdy, Thompson, and Tobin (1965) have stated that Coxsackie group B viruses are an important cause of both upper and lower respiratory tract infections in children, especially during the summer; they isolated several serotypes from such cases, though Johnson, Bloom, Forsyth, Mufson, Webb, and Chanock (1963) did not find a statistically significant association between Coxsackie B infection and lower respiratory tract disease in children.

This paper describes acute fatal pneumonia in two children occurring in 1960 during an epidemic of Coxsackie B5 infection. Coxsackie B5 virus was isolated from the lungs of each of them after death.

\section{CLINICAL HISTORIES}

CASE 1 A girl aged 8 weeks was admitted in July 1960 with a history of having had a bout of diarrhoea and having become cyanosed. On examination she was cyanosed and ill-looking; breath sounds were harsh, rhonchi and crepitations being heard over both lung fields. Her pulse eight hours after admission was $192 / \mathrm{min}$., and the temperature $104^{\circ} \mathrm{F}$. The child remained cyanosed in spite of oxygen therapy, and died an hour later. At necropsy, 42 hours after death, the larynx and trachea appeared normal, though the lining of the main bronchi was slightly reddened. The lungs were in places collapsed, in places emphysematous, and haemorrhagic, mainly posteriorly.

Received for publication 30 : une 1965.
CASE 2 A girl aged 17 months was admitted in August 1960 with a history that she had had earache and vomiting one week earlier, but this had subsided on treatment with penicillin and streptomycin. On the day of admission she refused all food and was sweating profusely. On examination she was pale and ill-looking, slightly cyanosed; respirations $48 / \mathrm{min}$., temperature $99^{\circ} \mathrm{F}$., pulse 180 . There were scattered rales. The heart was not enlarged. The following day she became dyspnoeic and was given hydrocortisone. The bronchi were sucked out; during this procedure the heart stopped beating. Accordingly the chest was opened for cardiac massage, and breathing was subsequently maintained by positive pressure through a tracheostomy. $X$-ray examination revealed extensive patchy pneumonia. The cerebrospinal fluid was normal. She became more cyanosed, bronchoscopy produced only scanty fluid, and she died.

At necropsy, two and a half days after death, a heavy growth of Staphylococcus aureus was obtained on culture from the tracheostomy wound, but there was only a scanty growth from the lungs and a moderate growth from the heart blood. The larynx and trachea were reddened. The main bronchi contained some debris, probably from the oesophagus. Both lungs were dark, congested and collapsed, especially posteriorly, and exuded frothy fluid when cut.

\section{HISTOLOGICAL OBSERVATIONS}

The lungs of both patients were similar histologically, though fibrinous membranes were more marked in the second patient, who lived longer after the onset. The following description will refer to both patients.

There appeared to have been a considerable outpouring of oedematous fluid into the alveoli; the alveolar walls were thickened and appeared somewhat oedematous and were infiltrated with mononuclear cells and large eosinophilic macrophages which in places were also found in the 


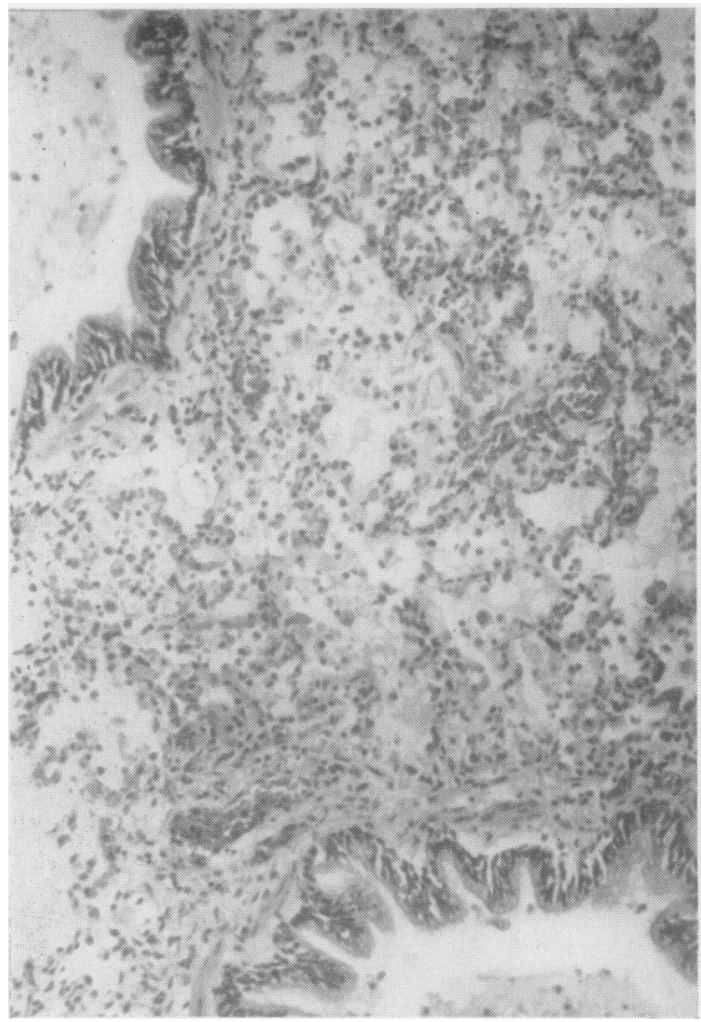

FIG. 1.

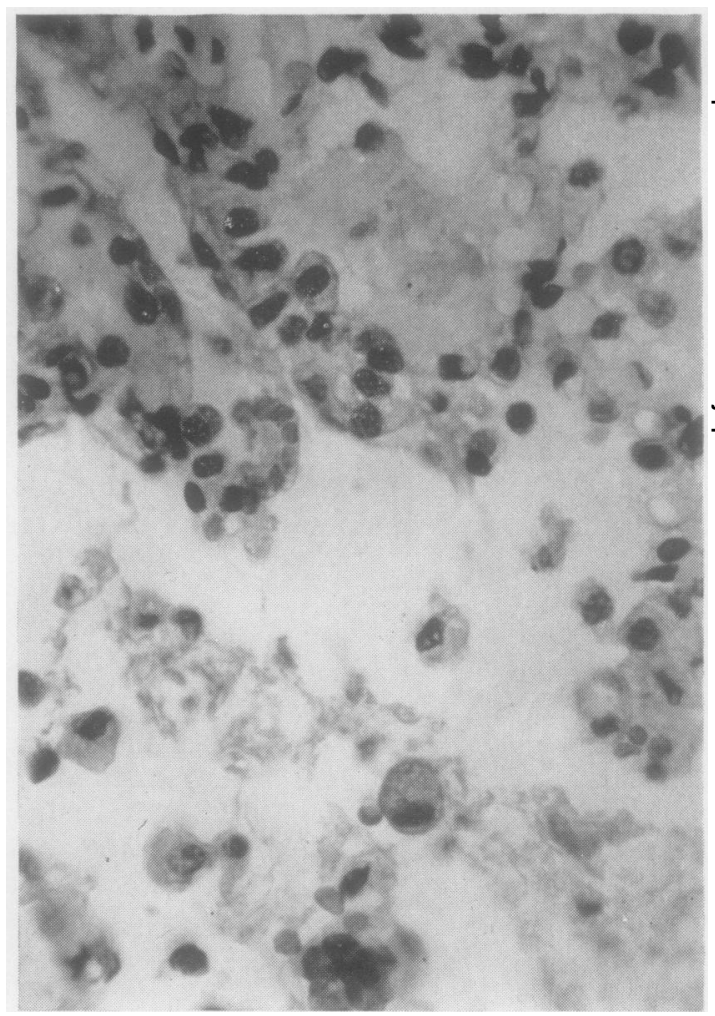

FIG. 2.

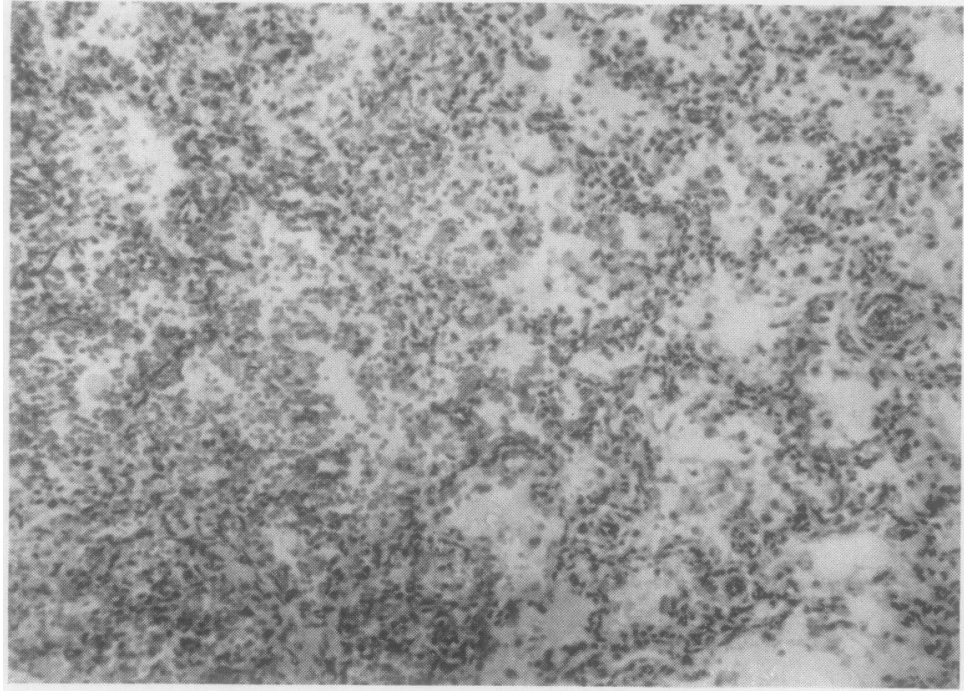

FIG. 3.
FIG. 1. Section of lung, the alveolar spaces contain erythrocytes and leucocytes mainly mononuclear and a protein precipitate.

Haematoxylin and eosin $\times 100$.

FIG. 2. Infiltration of alveolar walls with mononuclear cells, some of which are macrophages with vacuolated cytoplasm (case 2). Haematoxylin and eosin $\times 400$.

FIG. 3. The alveolar walls are infiltrated with darkly staining cells, and there has been haemorrhage into the alveoli (case 1).

Haematoxylin and eosin $\times 100$. 


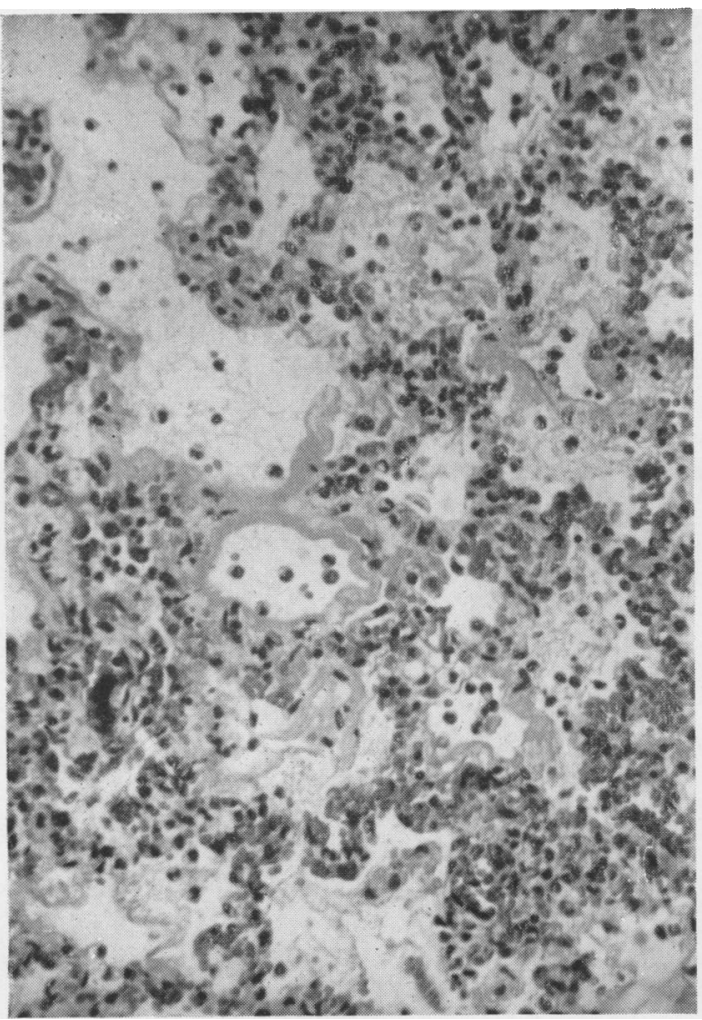

FIG. 4.

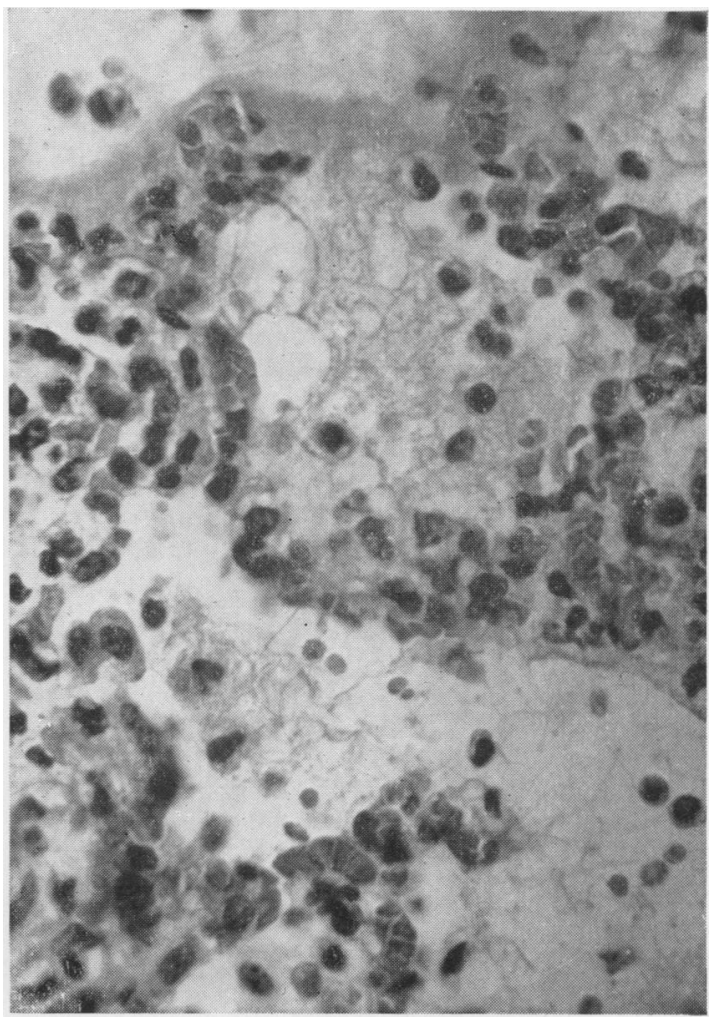

FIG. 5.

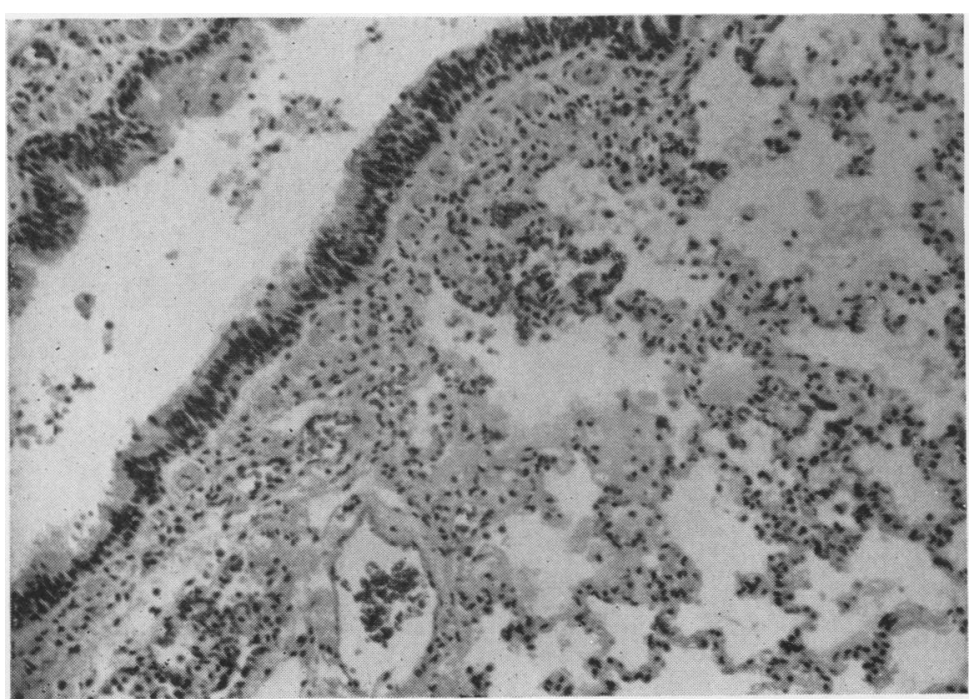

FIG. 4. Thick layers, in places appearing hyaline, lining some alveolar walls. Alveolar spaces contain mononuclear cells and a few polymorphs (case 2). Haematoxylin and eosin $\times 165$.

FIG. 5. Thickening and increased cellularity of the alveolar walls can be seen. There is a fibrinous mesh in the alveoli (case 2). Haematoxylin and eosin $\times 400$.

FIG. 6. The bronchial mucosa is well preserved even two days after death. The alveolar walls are congested and there is some precipitated protein in the alveoli. Haematoxylin and eosin $\times 100$.

FIG. 6. 
alveolar spaces (Figs. 1 and 2). Polymorphonuclear leucocytes, though present, were scanty. In places considerable extravasation of erythrocytes into the alveoli had taken place (Fig. 3). In numerous scattered foci many of the smaller air passages and alveoli were lined by a well-defined hyaline membrane which appeared to be composed of fibrin (Fig. 4), and a fibrin mesh filled many of the alveoli (Fig. 5). Elsewhere in the lung the alveolar oedema was comparatively scanty and there was little fibrinous exudate, the overall appearance rather resembling that commonly found in 'cot deaths'. The remarkable feature in both cases was the total absence of any clear abnormality of the bronchial epithelium or obvious inflammatory infiltration of the bronchial walls (Fig. 6). Hyaline membranes were much more prominent in case 2 than in case 1 . This is perhaps not surprising because the pneumonia in case $\mathbf{2}$ had lasted longer.

\section{DISCUSSION}

In the summer of 1960 , at the time these two children died, there was a widespread epidemic of Coxsackie B5 infection in the Birmingham area. It is therefore difficult to be certain that the virus isolated caused the disease. It seems probable however, that it was not merely a 'passenger'; first, because the histo $-\Rightarrow$ logical picture in both cases was basically similar, the pathological process being confined to theo alveolar walls (cyanosis was a prominent sign in을 both children); secondly, because it is known there $\frac{\bar{p}}{\mathrm{~s}}$ are many instances of isolation of Coxsackie $B \widetilde{\Phi}$ viruses from pneumonia in children, of other serotypes as well as B5.

The staphylococci isolated at necropsy from case $2 \vec{\circ}$ appear to have been derived from a terminal hospital $\vec{\omega}$ infection of the tracheostomy wound. There is noo evidence that they were responsible for the pneu-용 monia, and the histological changes found do not suggest this.

I am indebted to Dr. A. H. Cameron for the histological preparations from both these cases and for helpfulo discussion of the histological features, and to Drs. W. Cant and W. Carey Smallwood for permission to reportthe clinical histories of these patients.

\section{REFERENCES}

Holzel, A., Parker, L., Patterson, W. H., Cartmel, D., White, L. L. R., Purdy, R., Thompson, K. M., and Tobin, J. O'H. (1965). G
Brit. med.J., 1, 614 .

Johnson, K. M., Bloom, H. H., Forsyth, B., Mufson, M. A., Webb, P. A., and Chanock, R. M. (1963). Amer. Rev. resp. Dis., 88, (part 2), 240 